\title{
Sistema de automação residencial utilizando placa Arduino e controlado remotamente por smartphones
}

Home automation system using arduino board and remotely controlled by smartphones

Leonardo Adam ${ }^{1}$, Eyad Yousef Ibrahim Yousef ${ }^{2}$ e Celso Becker Tischer ${ }^{3}$

${ }^{1}$ Universidade Federal de Santa Maria, Coordenadoria Acadêmica, Cachoeira do Sul, Brasil leonardo.adam96@icloud.com; eyadyousef88@gmail.com; cbtischer@gmail.com

\section{Resumo}

Este artigo apresenta um projeto de automação residencial baseado em Arduino, tendo como finalidade controlar a luminosidade de lâmpadas, ajustar abertura e fechamento de uma cortina, além de encher e esvaziar uma banheira com controle de nível. Para executar tais operações, um aplicativo para Smartphone foi criado, onde o mesmo transmite os dados via Bluetooth para o Arduino e este processa e executa a ação solicitada. Foi desenvolvido um sistema de pequeno porte atendendo aos requisitos, com possibilidade de expansão para um sistema maior.

Palavras-chave: Arduino; Bluetooth; Smartphone

\section{Abstract}

This article presents a residential automation project using an Arduino, with the purpose of controlling the luminosity of lamps, opening and closing a curtain, filling and emptying of a bath with level control. To accomplish these, a smartphone control APP was developed, where transmits data via bluetooth to the Arduino platform, which process and performs the requested action. A small system that comply with the requirements was developed, with the possibility of expansion to a larger system. 


\section{Introdução}

A automação iniciou na indústria com o intuito de tornar os processos mais automáticos, padronizados e reduzir a necessidade de intervenção humana nos processos, assim reduzindo custos e tornando os processos mais rápidos e produtivos, podendo ser executados de forma ininterrupta segundo Saullo (2005). A automação é realizada com a ajuda de controladores, sensores e sistemas supervisórios, e atuam no controle de motores, atuadores pneumáticos, resistências, sistemas de refrigeração, dentre outros processos industriais.

A indústria foi marcada por 4 grandes revoluções, sendo a primeira no século XVIII na Europa. Houve a inserção de sistemas a combustão de carvão, onde surgiu a máquina a vapor e a locomotiva. Iniciando assim um conceito primitivo de automação, no qual a máquina a vapor substituiu parte da mão de obra braçal em industrias têxtis. Na segunda revolução industrial foi quando houve o emprego da energia elétrica nos acionamentos de motores e sistemas de parada de segurança, geralmente implementados em motores elétricos que substituíram os motores a combustão. A terceira revolução industrial gerou grande parte dos métodos e implementos empregados atualmente, houve grande avanço da informática, robótica e telecomunicações, trazendo CLPs (controladores lógicos programáveis), IHMs (interface homem máquina) e sistemas supervisórios. A quarta revolução industrial estamos vivendo no atual momento, com o surgimento de IoT (internet of things, ou internet das coisas) que se encontra em ascensão no mercado, assim como a comunicação via wireless dos equipamentos, de acordo com Moraes e Castrucci (2010).

Com a automação industrial surgiram diversos dispositivos lógicos programáveis sendo DSP, CLP, PIC, Arduino, entre outros, e cada modelo de equipamento utiliza uma linguagem, especificações, capacidade de processamento e de comunicação distintos. Então surgiu a ideia de automação residencial, utilizando principalmente os conceitos da quarta revolução industrial, com o intuito de ter controle de equipamentos remotamente, e até controle automático de alguns. Ainda é um sistema caro, porém está se tornando popular, tendo como exemplo, casas com sistemas automatizados para controle de temperatura (ar condicionados e aquecedores), controle automático de cortinas e persianas, controle de irrigação, e até controle da iluminação, trazendo não só praticidade, mas também economia, tanto de energia quanto até a possibilidade de realizar algumas tarefas onde seria necessário um empregado.

A Figura 1 apresenta a curva S da tecnologia, no atual momento a automação residencial encontra-se em uma fase de amadurecimento e ao mesmo tempo na fase de take-off (decolagem em tradução literal, que remete a um grande aumento na utilização) onde busca-se encontrar sistemas mais baratos e com grande eficiência, para não atingir somente residências de alto padrão, mas também encontrar-se em casas intermediárias, onde em um futuro além de realizar somente a automação, pode-se incorporar um sistema supervisório, integrado a micro geração e outros sistemas, conforme Angeloni (2013).

Figura 1 - Curva S da tecnologia

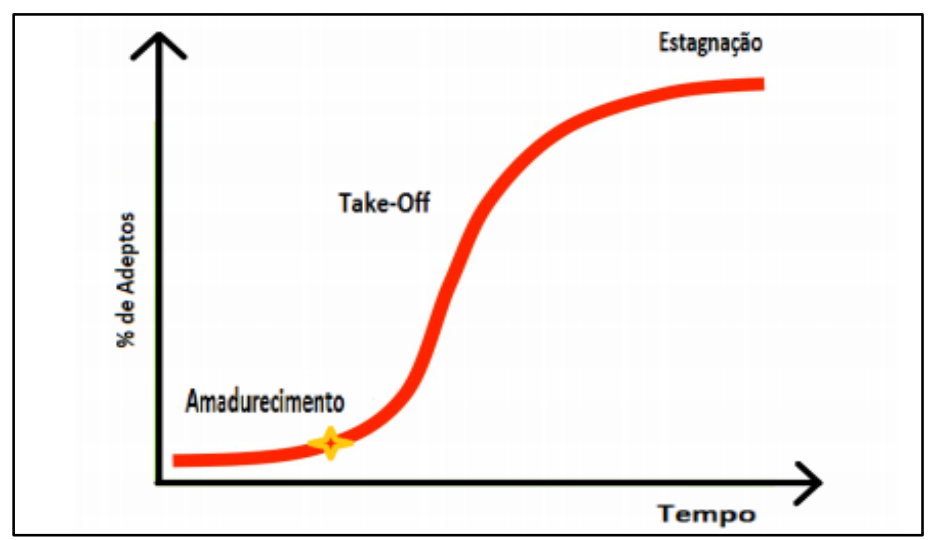

Fonte: (SANTOS. 2013) 
Levando em consideração os atrativos da automação residencial, este trabalho apresenta o controle individual de quatro lâmpadas LED, acionamento de uma cortina através de um servo motor, no qual é adotada a variação de 0 a $100 \%$ de abertura e fechamento, e controle do nível de água em uma banheira. Os dados executados são mostrados em um display LCD com status dos estados atuais solicitados pelo usuário. A linguagem utilizada para o projeto foi a linguagem C, sendo uma linguagem mais fácil de ser modificada e melhor compreendida e para isso foi utilizado o Arduino Mega, que tem um microcontrolador ATmega2560 incorporado.

\section{Desenvolvimento}

O objetivo é desenvolver um sistema de automação residencial que traga uma praticidade em algumas ações do dia a dia, proporcionando em um único aparelho o poder de executar tarefas distintas sem a necessidade de deslocamento. Para isso o projeto foi dividido em 3 etapas, sendo elas: 1) Desenvolvimento da programação em linguagem C; 2) Criação de um aplicativo utilizando a ferramenta de acesso livre, como a da plataforma MIT APP inventor; e 3) Implementação prática utilizando componentes eletrônicos junto a um Arduino.

\subsection{Primeira Etapa}

O Arduino Mega mostrado na Figura 2 possui entradas e saídas digitais, algumas dessas podem ser conFiguradas como saídas de PWM (Modulação por Largura de Pulso). Possui uma quantidade de armazenamento de memória suficiente para o processamento dos dados utilizados no projeto. A implementação em linguagem C foi dada pela facilidade na execução de comandos lógicos e aritméticos, sendo comandos aritméticos para controle dos níveis de luminosidade das lâmpadas e da abertura da cortina e comandos lógicos para acionar os equipamentos utilizados.

Figura 2 - Arduino Mega

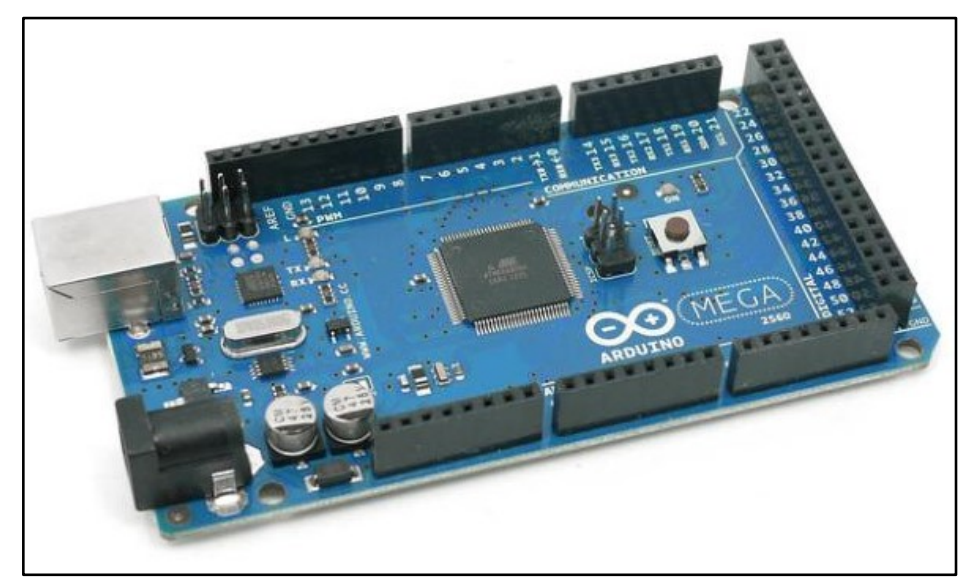

O primeiro passo foi a elaboração de um fluxograma, apresentado na Figura 3, onde estão contidas e organizadas todas as funções do projeto, elaborado para obtenção de um programa com característica simples e direta, permitindo que o Arduino execute rapidamente as rotinas.

O fluxograma divide-se em três partes distintas: o controle das lâmpadas, do nível de água da banheira e da cortina. As lâmpadas possuem comandos idênticos, como o comando "Liga", que leva a luminosidade diretamente ao nível máximo, o 
comando "Desliga" interrompe o fornecimento de energia para lâmpada, e os comandos "Aumenta" e "Diminui" modificam o nível de luminosidade em dez por cento para mais e para menos respectivamente.

Figura 3 - Fluxograma da programação desenvolvido

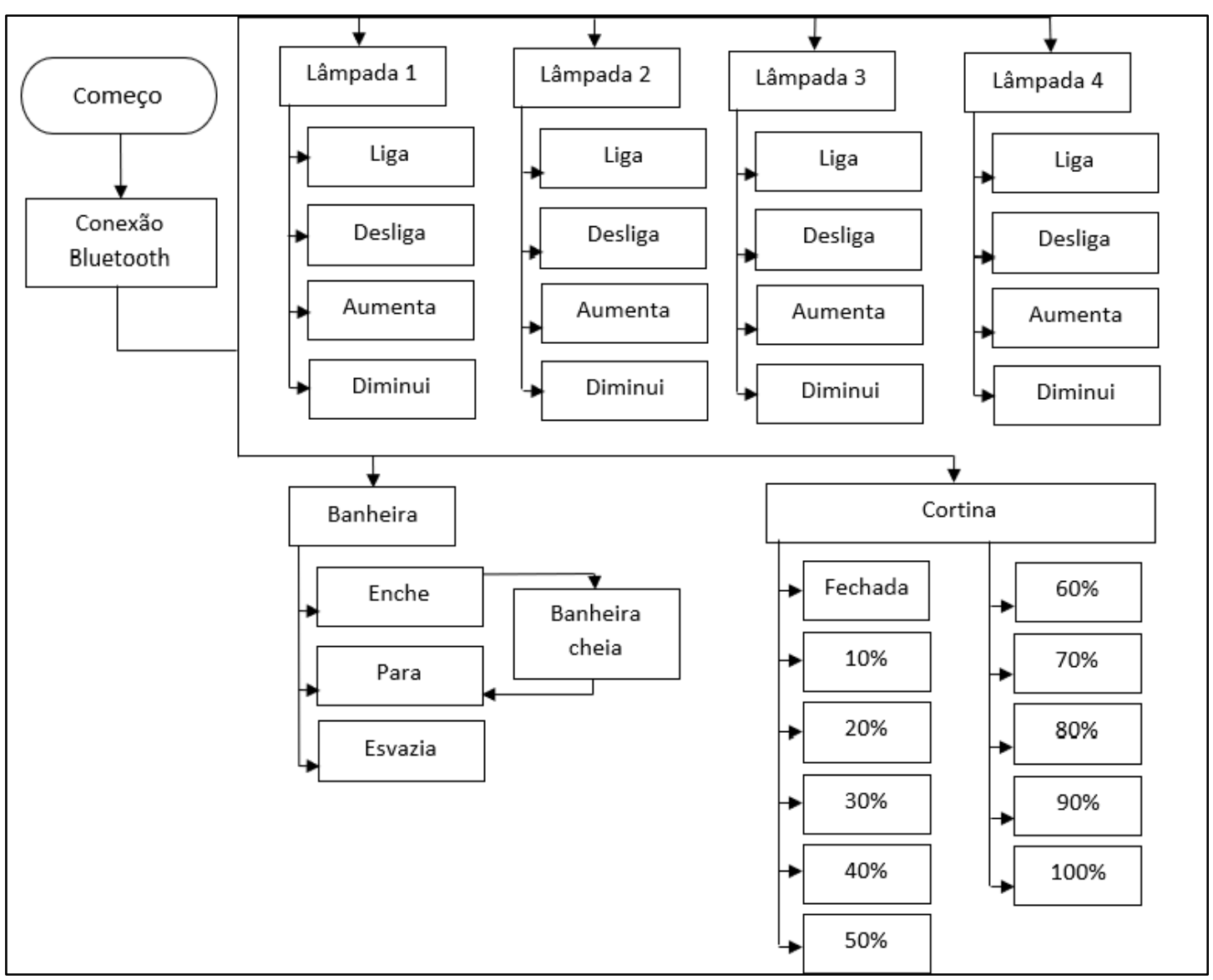

A banheira possui o comando "Enche" que bloqueia a válvula de escape da mesma e libera a entrada de água, já o comando "Para" interrompe a entrada de água. O comando "Esvazia" libera a válvula de saída e bloqueia a entrada de água na banheira se a mesma estiver ativada. O comando "Banheira cheia" é executado automaticamente quando é detectado que a banheira está cheia. Para a cortina existem onze posições possíveis, de totalmente aberta até totalmente fechada, podendo ser modificada em níveis discretos, a cada dez por cento.

A programação foi elaborada para acionar as lâmpadas LED's controlando o nível de luminosidade. Esta operação foi alcançada utilizando as saídas PWM do Arduino para variar a tensão de alimentação dos LED’s. No controle de abertura e fechamento da cortina foi utilizado um servo motor, variando o ângulo de $-90^{\circ}$ até $90^{\circ}$. Para a programação da banheira, foi utilizado uma lógica Bit, onde os estados são '0' lógico para desativado e ' 1 ' lógico para ativado, além do sensor de nível, onde um "push button" foi utilizado para que o programa recebesse o sinal do sensor. Todas as ações realizadas são exibidas em um display LCD. 


\subsection{Segunda Etapa}

Para o controle das tarefas desejadas, um aplicativo para smartphone foi criado na plataforma MIT APP inventor. Nessa plataforma foi realizada o envio de dados através do Bluetooth fazendo com que o Arduino receba o comando e execute no código a tarefa desejada. As saídas são alteradas conforme o comando solicitado, assim, fazendo com que o equipamento execute a tarefa. Na Figura 4 são exibidos os blocos utilizados na plataforma do MIT para o pareamento do smartphone com o módulo Bluetooth conectado ao Arduino.

Figura 4 - Comandos para a conexão via bluetooth

when ListPicker1 $v$.BeforePicking

do set ListPicker1 $v$. Elements $~$ to CBluetoothClient1 $v$. AddressesAndNames $v$

Na Figura 5 são apresentados os blocos para os comandos da lâmpada 1, para cada caractere que é enviado ao Arduino é atribuído uma função diferente, o restante das lâmpadas e equipamentos seguem o mesmo padrão de blocos para comando, porém com caracteres diferentes dos já escolhidos.

Figura 5 - Blocos utilizados para comando da lâmpada 1
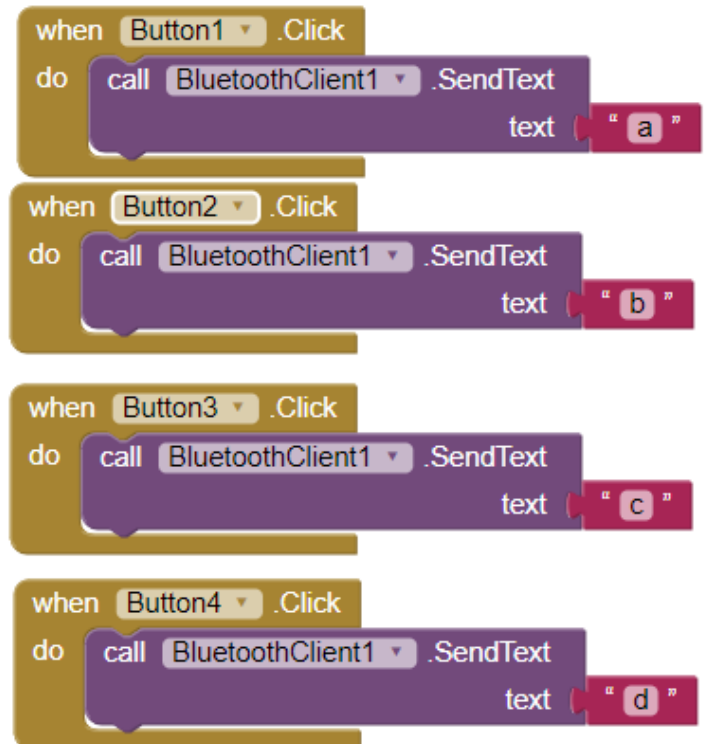

Após gerar o código na plataforma, foi gerado o aplicativo utilizado no Smartphone com sistema Android, onde cada ícone refere-se a um "Button", conFigurado com um nome para fácil identificação de qual ação realiza. A interface do APP Inventor é apresentada na Figura 6. 
Figura 6 - Interface do APP.

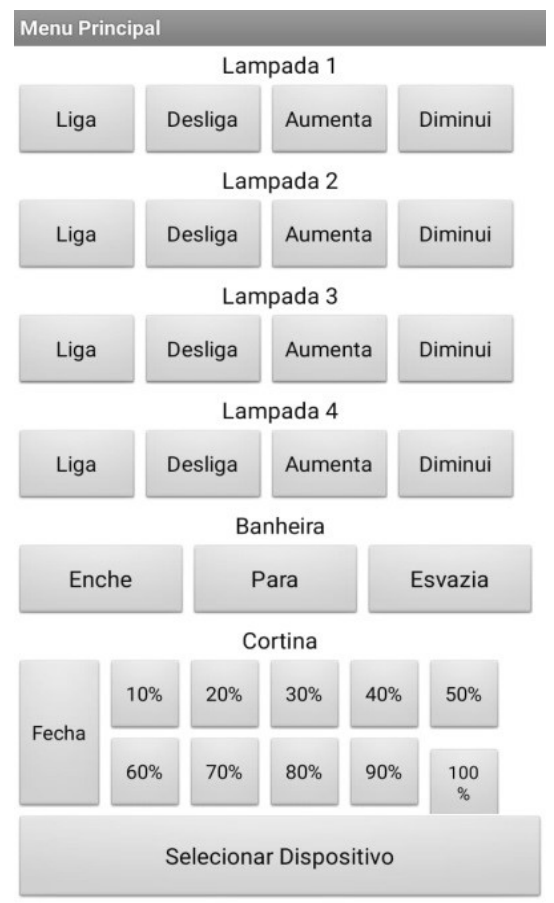

\subsection{Execução do projeto na prática}

Após todos os passos anteriores foi implementado na prática o projeto como mostrado na Figura 7, para isso foram utilizados os seguintes componentes: 4 LEDs para simular as lâmpadas; um servo motor para simular o motor de abertura e fechamento da cortina; 2 LEDs para simular a ação de encher e esvaziar a banheira; um "push button" para o sensor de nível; resistores para controle de corrente dos LEDs; display LCD para visualização das ações executadas pelo usuário; 1 potenciômetro para regular o contraste do display e o Arduino Mega, para receber os comandos e executar as tarefas regidas pelo usuário.

Figura 7 - Implementação prática do sistema de automação residencial.

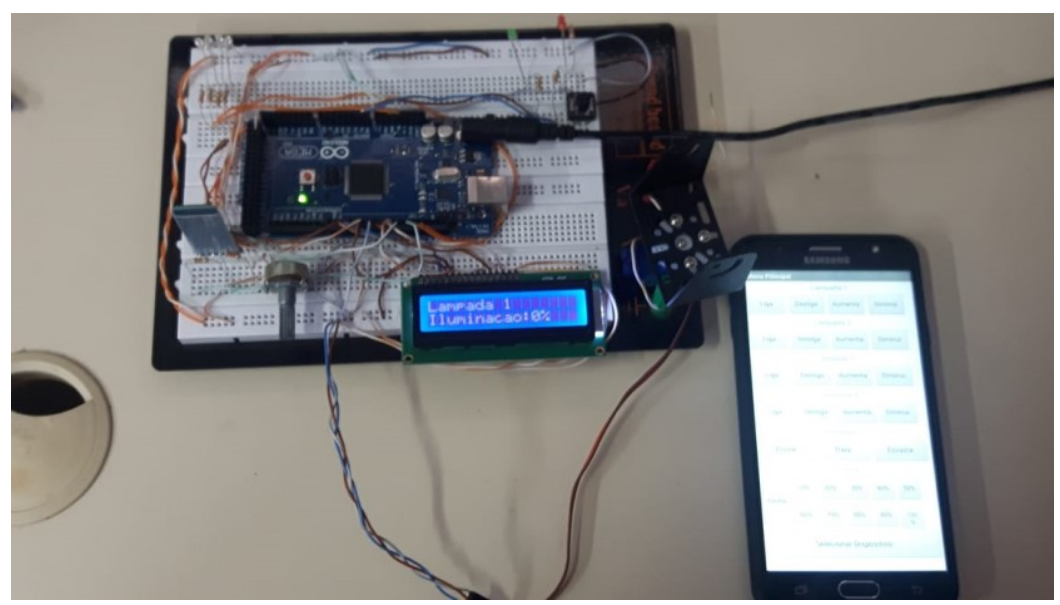




\section{Resultados}

Ao final do projeto foi atingido um resultado satisfatório. O sistema provou-se eficiente e atingiu os objetivos propostos, tornando possível o controle dos equipamentos solicitados a uma distância de aproximadamente 10 metros, suficiente para uma residência de médio porte. Para a aplicação em uma residência são necessárias algumas alterações nos equipamentos utilizados, como um dimmer para as lâmpadas, e um sensor de nível para a banheira por exemplo, porém a lógica de programação e o sistema de bluetooth permanecem o mesmo.

\section{Conclusões}

Este artigo apresentou um projeto de automação residencial baseado em Arduino no qual mostrou-se prático, de fácil instalação e viável economicamente comparado com sistemas existentes no mercado. As atribuições do projeto apresentado com LED's, push button, servo motor e display LCD pode facilmente ser expandido para controle de ventiladores e ar condicionado, que são equipamentos comumente controlados a partir de automação residencial na inserção de sensores de temperatura ao Arduino. A partir desse trabalho foi possível perceber que a utilização da plataforma microcontrolada aliada a uma interface amigável e funcional possibilita uma gama de aplicações, pela facilidade de informações, bibliotecas e funções transparentes que facilitam o acoplamento de sensores, atuadores e outros equipamentos a esta ferramenta. Como trabalho futuro pretende-se substituir a comunicação via bluetooth por uma rede wifi.

\section{Referências}

PEDRONI V A, Circuit design with VHDL .London, England: MIT Press, c2004 xii.

MALVINO A P, Microcomputadores e microprocessadores. São Paulo: McGraw-Hill, c1985

WAKERLY J F, Digital design: principles and practices . 2nd ed. Englewood Cliffs Prentice-Hall 1994

MORAES C C, CASTRUCCI P L. Engenharia de automação industrial. 2a ed. Rio de Janeiro: GEN LTC 2010.

CARDOSO S. - O que é Automação Industrial? 6 benefícios dos projetos para indústrias [internet], UFRJ: fluxo consultoria; available: http://fluxoconsultoria.poli.ufrj.br/blog/tecnologia-informacao/o-que-e-automacao-industrial/

ANGELONI G C, Automação Residencial [thesis]. Florianópolis: Departamento de Automação e Sistemas, Centro tecnológico UFSC/2013: 4 p. 